\title{
INVESTIGATION OF FUEL CONSUMPTION AND EMISSIONS OF TRUCKS BY DESIGNING OPTIMAL BODY
}

\author{
Mehrdad Khosravi \\ Young Researchers and Elite Club, Borujerd Branch, Islamic Azad University, Borujerd, Iran \\ mehrdad.khosravi67@gmail.com \\ Majid Oveisi \\ Lecturer, Department of marine Engineering, Chabahar, Maritime University. \\ Ebrahim Mahmoudpour \\ Islamic Azad University, Boruojerd Branch, Mechanic Faculty
}

\begin{abstract}
One of the primary concerns in automotive industry is energy saving, protecting the global environment and fuel consumption reduction. The main objective for this paper is to study the possibility to improve the aerodynamic performance for boosting fuel economy of trucks, by optimal designing of supplementary devices. This will be carried out by using integrated computational fluid dynamic and genetic algorithm for simulation and geometry optimization of applied devices. In addition, simulation results are verified by experimental results in wind tunnel. For this purpose, effects of various supplementary devices and configuration are added to space between cabin and cargo compartment to stabilize the vortex and decrease the drag resistance force. Finally, the geometry of appended device with considering the installation and packing conditions, is optimized by using genetic algorithm. Through the analysis of airflow contours and optimization procedure, results indicates that using two plates at the sidewalls of gap with optimized length and installation angle can reaches the maximum reduction of drag force and fuel consumption 20 and $10 \%$ respectively.
\end{abstract}

Keywords: Fuel consumption, Emissions, Aerodynamic, CFD, Optimization (GA), Drag reduction

\section{INTRODUCTION}

In order to evaluate the vehicle aerodynamic performance, wind tunnel and finite element method (FEM) are utilized by manufactures. Wind tunnels are used to simulate air (fluid) flows over vehicles, which is in contact (friction) with the surrounding environment [1-4]. Given the high cost and required equipment for the wind tunnel, the alternative simulation method based on FEM, is applied to check the vehicles aerodynamics performance $[5,6]$.

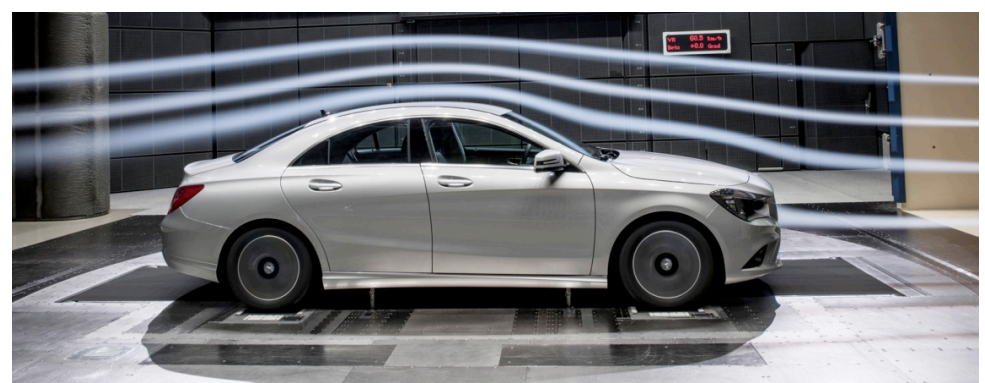

Figure 1. Pressure flow around vehicle in wind tunnel

As shown in figure (2) aerodynamic forces are includes: Drag, Lift, Lateral force, Rolling Moment, Pitching Moment, and Yawing Moment. These forces are effective in fuel economy, emissions, vehicle controllability and noise-vibration-harshness (NVH). 


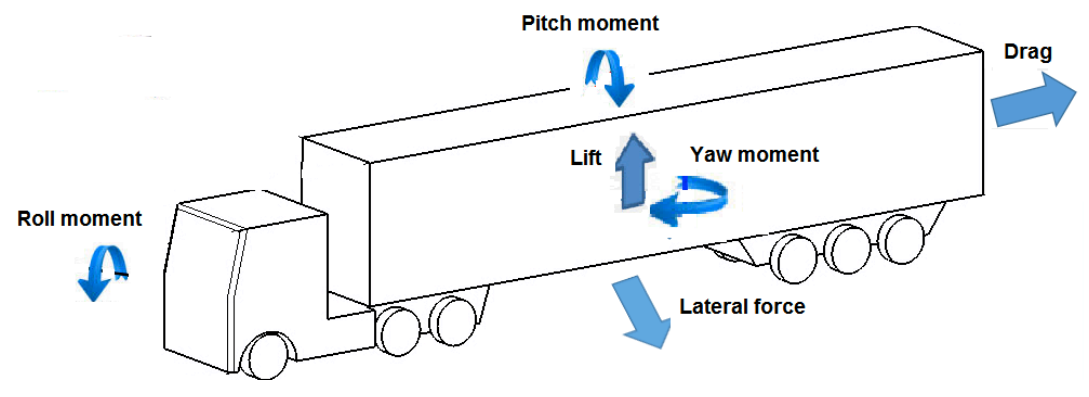

Figure 2. Aerodynamic forces

The drag force is the dominating resistance force, which acts on commercial vehicles and trucks in highway. Drag force at high speeds is one the main resistance force that increases fuel consumption significantly. Increasing speed from $55 \mathrm{mph}$ to $65 \mathrm{mph}$ for example increases drag by about 40 percent, resulting in a 10 to 15 percent increase in fuel consumption [7,8]. Drag reduction techniques are mainly divided into two categories; Design optimal body shape in manufacturing process, which usually is in conflict with body structure and style parameters.

Heavy vehicles due to their large frontal area and bluff shapes are aerodynamically inefficient and take up to $65 \%$ of fuel to overcome drag. As mentioned by Hsu and Davis [9], it is estimated that with a drag reduction of about $40 \%, 10,000 \mathrm{USD} /$ year/vehicle can be saved. Due to the high cost of development and required testing for any changes in sample model in the wind tunnel. So, before production original sample FEM is utilized to analyze the influence of aerodynamic parameters and finding optimal body shape. In the case of trailers and trucks, the cab shape has huge impact on the formation of airflow around the body and creation of vortices (figures 4 and 5). Therefore, proper design of the cabin can significantly affect the drag reduction. Previous studies $[10,11]$ investigated the effects of different types of roof deflectors, side deflectors and chassis fairings on vehicle aerodynamic improvements. Mazyan [10] analyzed the effect of applying drag reducing devices on a sedan, sports utility vehicle (SUV) and a tractor-trailer model to improve the fuel consumption of the vehicle. They used CFD to analyze the percent drag reduction due to the use of different drag reducing devices. Ortega et al [11] employed a full-scale wind tunnel to investigate the changes in the drag coefficient that arise from the installation of supplementary devices for class 8 heavy vehicles. They obtained a better understanding of how different devices affect the performance of other devices installed simultaneously. Bruneau et al. [12]. Singh [13] could reach drag reduction of up to 18 percent by implementation of base flaps in heavy and road vehicles. Håkansson and Lenngren [14] presented devices for Volvo FH trailer. Their results demonstrate that fuel Aerodynamic trailer devices have a great potential of reducing drag compared to the tractor. Also, they showed that Side skirts and Frame extension have a large potential to prevent turbulence and vortices in these regions.

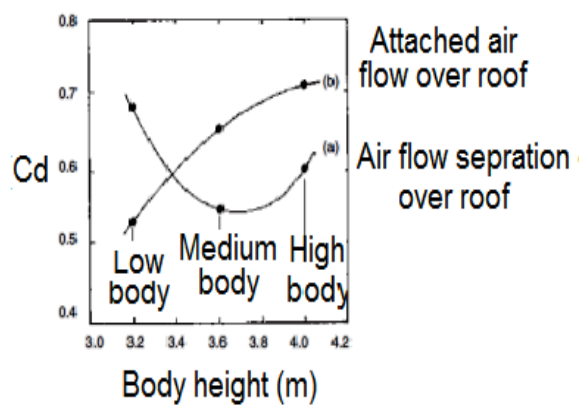

Figure 3. Effects of cab shape and height upon the drag coefficient

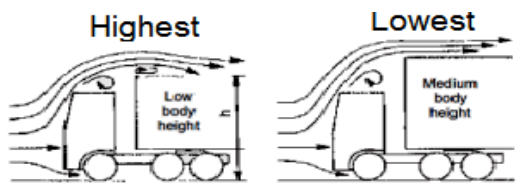

a) Sharp body
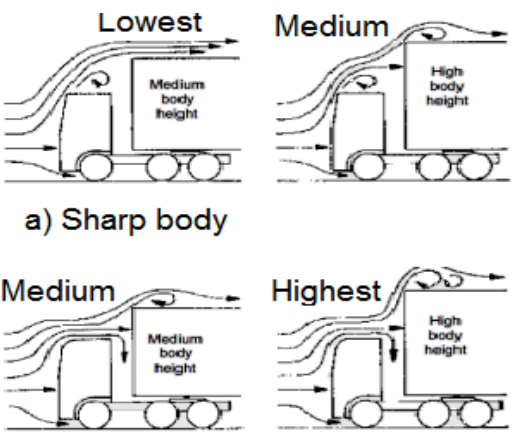

b) Rounded body

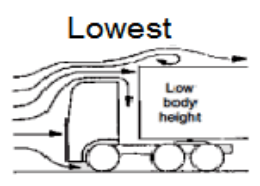

hounded body
Figure 4. Effects of wind screen height and angle on air flow over cab roof 
Previous studies $[7,15]$ demonstrated that in commercial vehicles total reduction of drag coefficient results in $12 \%$ improvement in fuel economy. Average mileages of trailers over a year is about 10000 mile which with considering $351 / 100 \mathrm{~km}$ fuel consumption rate, it consumes 56000 liter (12300 gallon) per year. By reducing the drag coefficient reduction, about $12 \%$ of fuel consumption reduces which equivalent 4000 pound for a year. Beside that with reduction of drag force, vehicles emissions and NVH reduces significantly. Kassim and Filippone [16] used various aerodynamic retrofitting techniques to reduce heavy vehicle drag and fuel consumption. They numerically simulated realistic on-road operations to represent the effectiveness of these retrofits on various vehicle weights and driving cycles. Their results demonstrated that fuel economy improvement could be achieved from less than $1 \%$ to almost $9 \%$ an annual mileage. Englar [17] studied the effect of the gap between the tractor and trailer. He used a generic truck model for wind tunnel tests. Hyams et al., [18] investigated unsteady aerodynamic flows affecting the fuel economy of Class 8 trucks by numerical solutions of the unsteady Reynolds-averaged Navier-Stokes equations using a parallel implicit flow solver have been given to investigate unsteady aerodynamic flows affecting the fuel economy of Class 8 trucks. Comparison of their numerical results with experimental shows that with increasing yaw angle the accuracy decreases, whilst excellent agreement with experimental data was obtained for the $0^{\circ}$ yaw angle while the $10 \mathrm{o}$ case had good agreement.

In this research a comprehensive CFD study are conducted to investigate the influences of supplementary parts on drag reduction of trucks. For this purpose geometry of main add-on parts are optimized by using genetic algorithm to reduce fuel consumption, emission and $\mathrm{NVH}$. The results of the current study provide optimal supplementary parts usage for improvement of heavy vehicle aerodynamic characteristics.

\section{Modeling and Simulation}

In this paper, Volvo truck FH12 specification and dimension is considered for the modelling (figure 5). As well as the large dimensions of the complete trailer model, the governing equations will go up, which result in complication and time consuming of FEM. Due to the symmetry of the vehicle, half of the vehicle is modeled to reduce required time for procedure simulation (figure 6).

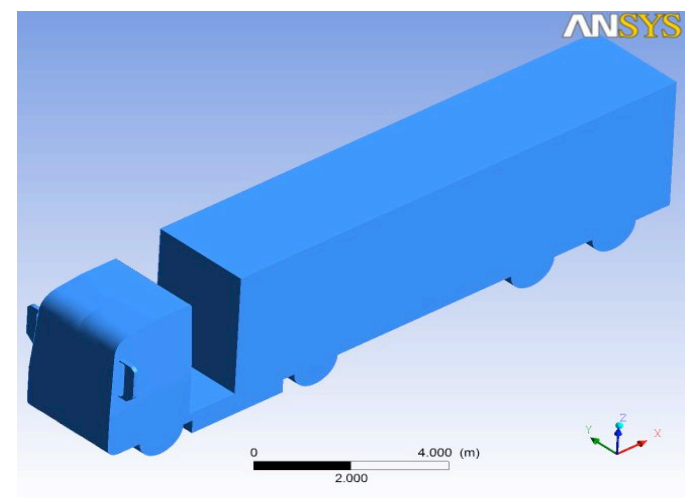

Figure 5. complete vehicle model

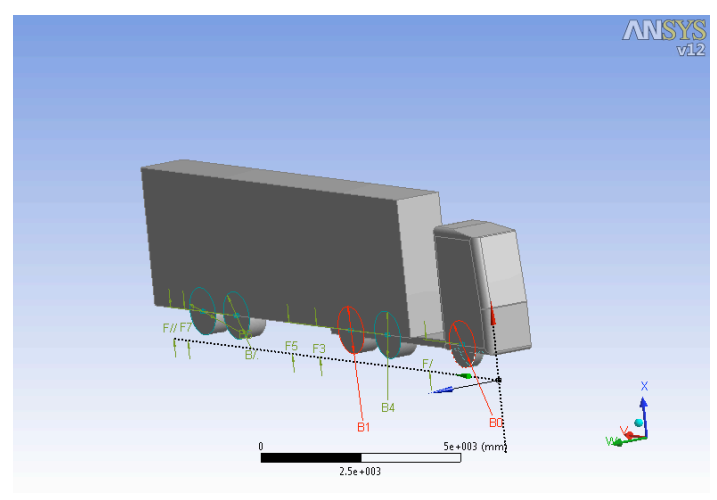

Figure 6. half-car model

In order to simulate the aerodynamic behavior vehicle, as shown in figure (7), CFD analysis of proposed model is carried out in virtual wind tunnel. Then boundary conditions are defined as figure (8). The boundary conditions of the trailer model in $1 \mathrm{~atm}$ and $25^{\circ} \mathrm{C}$ and steady state are defined. Boundary condition for input air is considered only air velocity and pressure of output air intends to be zero. Also, surrounded wind tunnel walls are considered non-slip and trailer body proposed to be no friction surface. Finally, trailer meshed model is illustrated in figure (9). 


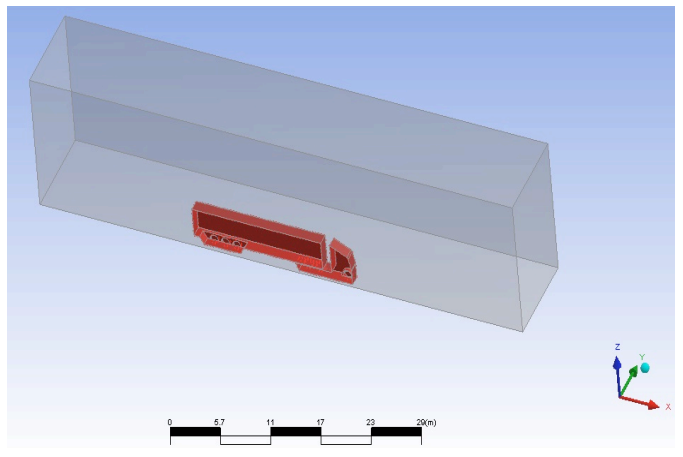

Figure 7. Trailer model in virtual

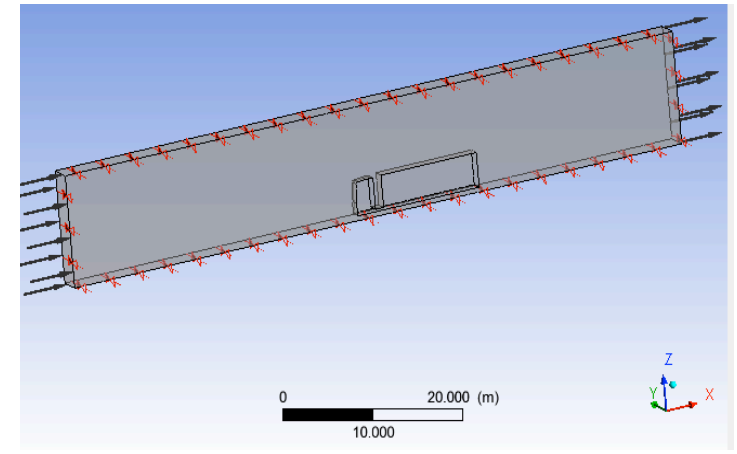

Figure 8. boundary condition

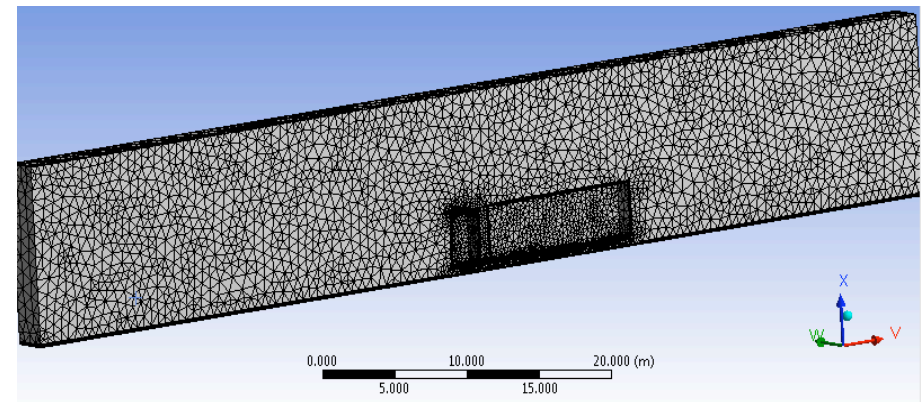

Figure 9. Wind tunnel and trailer mesh model

\section{OPTIMIZATION}

In order to minimize the drag force with considering the shape and layout of add-on parts, a constrained optimization procedure are developed based on genetic algorithm. For this purpose, as shown in the figure (10) the length (L) and angle $(\theta)$ of sidewall (supplementary part) are considered as variables to minimize drag force whilst its layout and variables range are assumed as a constraint function.

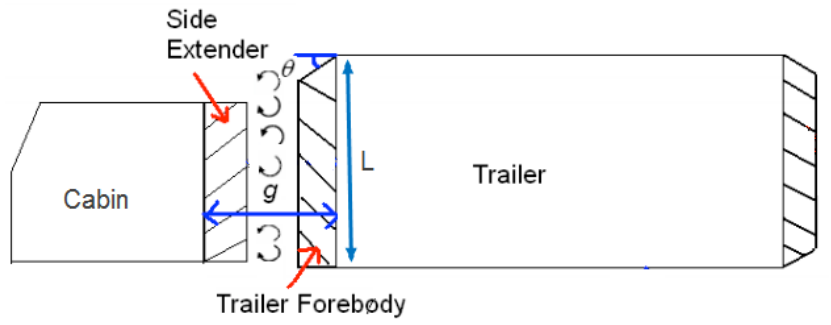

Figure 10. Configuration and geometry of two plates installed on sidewall gap

With optimal geometry of added device in gap, the drag resistance force minimized by stabilizing the vortices depicted on figure (10). The procedure of a GA is composed by iteration of generation through the following six steps $[19,20]$ :

- Creating an initial population $\mathrm{P}_{0}$,

- Evaluation of the performance of each individual $\mathrm{p}_{\mathrm{i}}$ of the population, by means of cost function,

- Selection of individuals and reproduction of a new population,

- Application of genetic operator, crossover for producing new generation, 
- Application of genetic operator, mutation for prevention of local minimum area (enhancing global optimization)

- Looping of steps $2-5$ to fulfillment of a criterion stop.

\section{RESULTS}

Due to that, the tests for trucks FH12 was carried out without the cargo in the wind tunnel, so for comparison the simulation results with experimental one, trailer body for FEM analysis is modeled without cargo. Simulation model is presented in figure (11) and air density and wind speed are considered $1.294 \mathrm{~kg} / \mathrm{m} 3$ and $23.6 \mathrm{~m} / \mathrm{s}$.

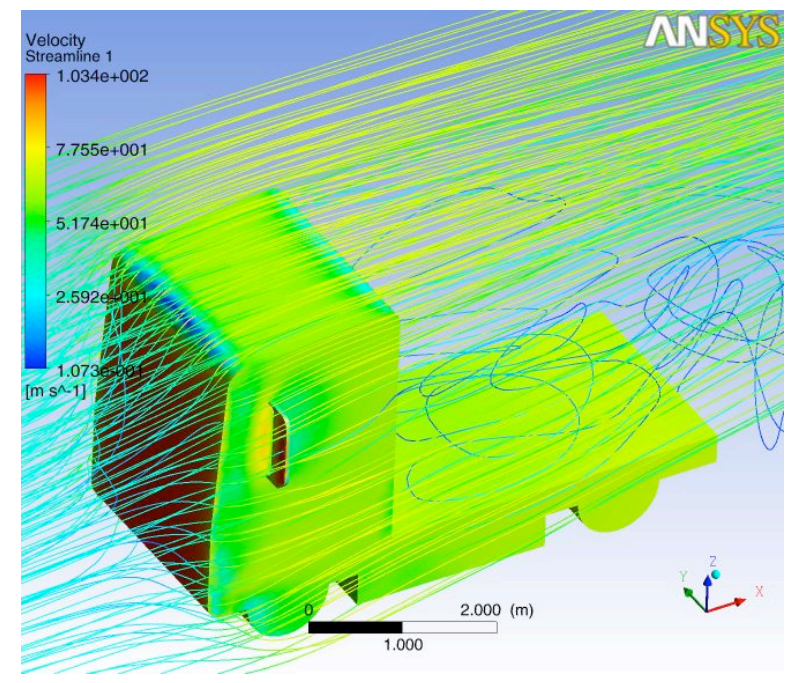

Figure 11. Pressure counter and air flow around FH12 model

Simulation results in figure (11) presents drag force as $2672 \mathrm{~N}$. In comparison with actual one $(2300 \mathrm{~N})$ in [21] it is $9 \%$ more, which is due to simplification of the model curves.

\section{OPTIMAL STRUCTURE FOR DRAG REDUCTION}

Front Fairings

As shown in figure (12) this device is installed on around of cargo compartment front surface. It deflects airflow and prevents flow separation, which causes reduction of drag force. Figure (13) illustrates pressure counter and airflow velocity around trailer.

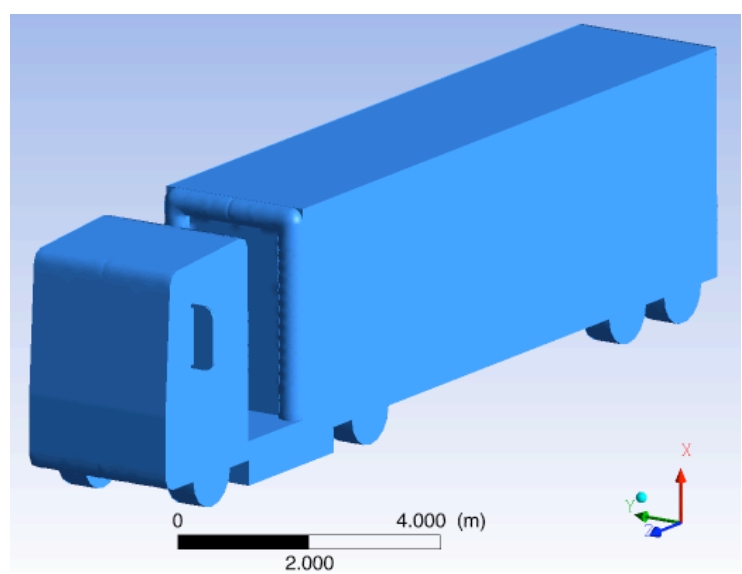

Figure 12. trailer model with front fairings

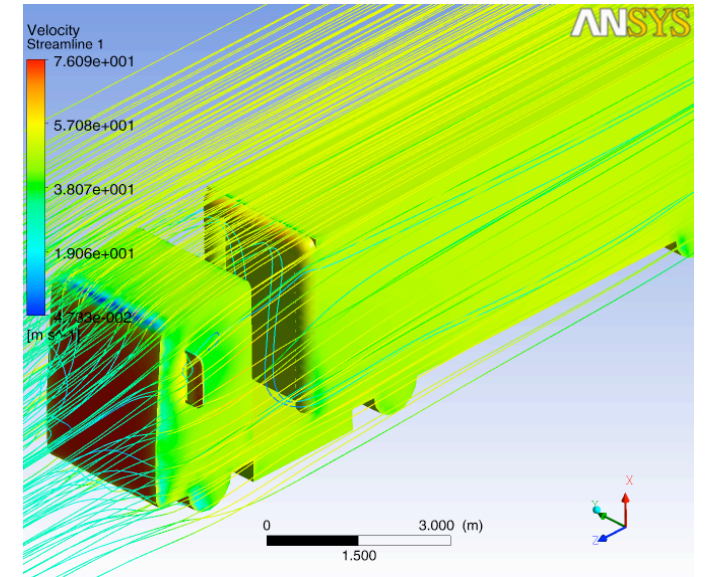

Figure 13. pressure counter and airflow velocity around trailer with front fairings 
Efficiency of various add-on devices on drag reduction

These supplementary parts are added simultaneously on trailer. Simulation results for various configurations are presented in table 1.

Table 1. Effects of various add-on devices on drag force

\begin{tabular}{|c|c|c|c|c}
\hline Configuration description & $\begin{array}{c}\text { Air velocity } \\
(\mathrm{m} / \mathrm{s})\end{array}$ & $\begin{array}{c}\text { Air density } \\
\left(\mathrm{kg} / \mathrm{m}^{3}\right)\end{array}$ & $\begin{array}{c}\text { Drag force } \\
(\mathrm{N})\end{array}$ & $\begin{array}{c}\text { Drag } \\
\text { reduction }\end{array}$ \\
\hline Basic model & 30 & 1.294 & 5215.6 & \\
\hline One plate at center of gap & 30 & 1.294 & 5201.2 & $0.27 \%$ \\
\hline Two plates at center of gap & 30 & 1.294 & 5198.3 & $0.33 \%$ \\
\hline Front fairing & 30 & 1.294 & 5207.8 & $0.15 \%$ \\
\hline $\begin{array}{c}\text { Two plates at sidewalls of } \\
\text { gap }\end{array}$ & 30 & 1.294 & 5179.3 & $0.7 \%$ \\
\hline
\end{tabular}

It is fairing obvious that, installation of two plates at gap sidewalls provide the most efficiency between various configurations in drag reduction. In other words, the optimal device among studied add-on devices is two filler plates installed on the gap sidewalls between the cargo compartment and cab. Therefore, in the optimization procedure, its geometry optimizes by using GA.

\section{GEOMETRY OPTIMIZATION OF SUPPLEMENTARY PART}

In this section, the dimensions of the sidewall piece mounted on the trailer (as a device which provide most impact on drag reduction) are optimized for enhancing minimum drag force. The main dimensions of the device are the angle and length of piece. So, the main objective of GA is determining the optimized value of its angle and length to reduce drag force. GA parameters are presented in table (2). Also, the optimization procedure for 50 iterations and the best selected next generations are illustrated in figure (14) and (15) respectively.

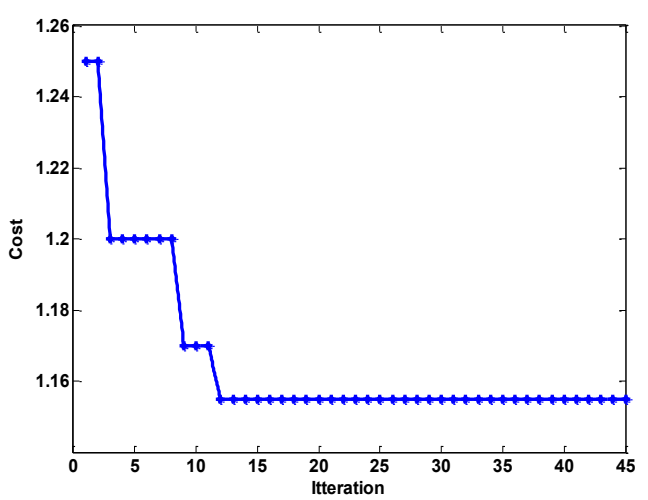

Figure 14. solution convergence in GA iterations

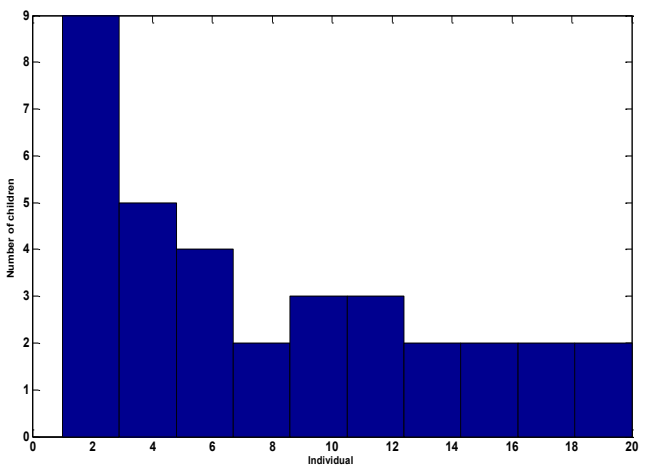

Figure 15. Child generation for 20initial population

Table (2) presents the optimization results for 50 iterations and selected solutions are with various length and angles are determined for each case. 
Table 2. Optimization results

\begin{tabular}{|c|c|c|c}
\hline Angle (Degree) & Length $(\mathrm{m})$ & Drag force $(\mathrm{N})$ & Drag reduction \\
\hline 0 & 0 & 5215.6 & \\
\hline 0 & 1 & 5179.3 & $0.07 \%$ \\
\hline 0 & 0.8 & 5171.2 & $0.86 \%$ \\
\hline 0 & 0.6 & 5174.6 & $0.78 \%$ \\
\hline 0 & 0.4 & 5189.6 & $0.5 \%$ \\
\hline 5 & 1 & 5175.9 & $0.76 \%$ \\
\hline 10 & 1 & 5170.3 & $0.87 \%$ \\
\hline 10.52 & 0.74 & 5169.4 & $0.88 \%$ \\
\hline 11.34 & 0.79 & 5170.2 & $0.88 \%$ \\
\hline 12.2 & 0.76 & 5176.3 & $0.75 \%$ \\
\hline 9.65 & 0.85 & 5173.3 & $0.79 \%$ \\
\hline 15 & 1 & 5180.8 & $0.66 \%$ \\
\hline 10 & 0.8 & 5172.7 & $0.82 \%$ \\
\hline 5 & 0.6 & 5178.9 & $0.7 \%$ \\
\hline 10 & 0.6 & 5183.6 & $0.61 \%$ \\
\hline 10 & 0.4 & 5189.7 & $0.5 \%$ \\
\hline
\end{tabular}

Results demonstrates that GA with considering packaging and installations constraints determines the best optimal solution of device geometry. It demonstrates that the best angle and length are 10.52 degree and 0.74 $\mathrm{m}$, which results in $0.88 \%$ drag reduction (force $45.8 \mathrm{~N}$ reduces). Figure (16) depicts the airflow and velocity counter around the trailer with optimized sidewall device mounted on the trailer.
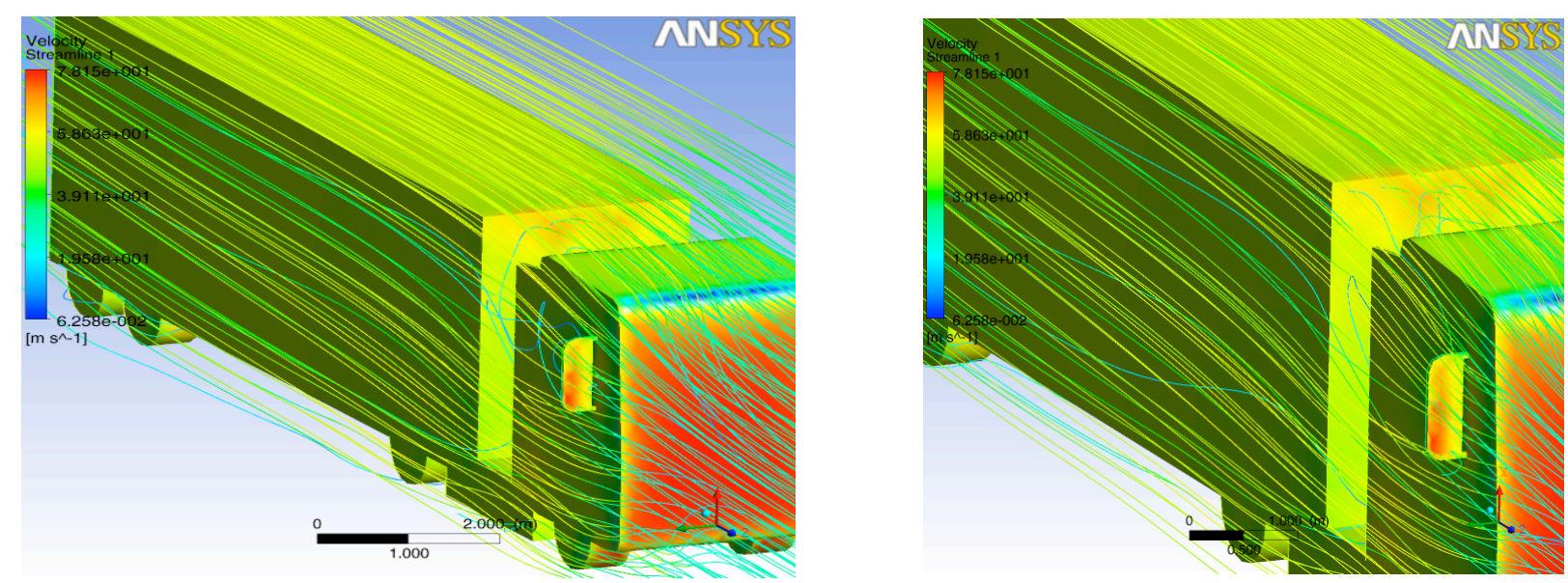

Figure 16. Airflow and velocity counter around trailer

\section{CONCLUSION}

Fuel consumption always is one of the key issues in the truck design, which significantly effects on emissions and costs. Therefore, the main objective of this paper is to design and optimization of the drag force reduction devices, which has main role in improving fuel efficiency. In this paper, trailer modeled and effects of supplementary parts for reduction of drag force investigated. For this purpose, at the first step, in order to verify the proposed model and simulation, enhanced results for basic model were compared by the experimental results in wind tunnel. Then main add-on devices effects on improving aerodynamic performance compared. Results indicated that the installation of two plates at gap sidewalls provide the most 
efficiency in drag and fuel consumption reduction. Finally, to minimize the drag force, the geometry of plates at the sidewalls optimized by GA with considering the installation and packing constraints, which results in obtaining the optimal length and angle of installation. Results indicated that with installation the optimized plates at the side of gap between cabin and cargo compartment, drag force reduces about $20 \%$, which, it can reduce fuel consumption about 4 to $10 \%$ over a year.

\section{REFERENCES}

Bellman M., Numerical Drag Reduction Studies on Generic Truck, MS thesis, Engineering of Washington University, Saint Louis, Missouri, 2009.

Chen G., Chen B., Li P., Bai, P., Ji C., Study of Aerodynamic Configuration Design and Wind Tunnel Test for Solar Powered Buoyancy-lifting Vehicle in the Near-space, Procedia Engineering 99, 2015, 67-72.

Gilkeson C.A., Toropov V.V., Thompson H.M., Wilson M.C.T., Foxley N.A. Gaskell P.H., Aerodynamic shape optimization of a low drag fairing for small livestock trailers, 12th AIAA/ISSMO Multidisciplinary Analysis and Optimization Conference, 2008, Victoria, British Columbia Canada.

Mahmoodi-k, M, Davoodabadi I, Višnjić V, Afkar A. Stress and dynamic analysis of optimized trailer chassis, Technical Gazette, 21, 2014, 599-608.

Shukri I.A., Akram A.M., Improvement of Aerodynamics Characteristic of Heavy Trucks, 3rd International Conference on Trends in Mechanical and Industrial Engineering (ICTMIE'2013) January 8-9, 2013 Kuala Lumpur (Malaysia).

Ortega J., Salari K., Investigation of a Trailer Underbody Fairing for Heavy Vehicle Aerodynamic DReduction, SAE International, Document Number: 2008-01-2601, 2008.

WSP Development and Transportation, Longer Semi-trailer Feasibility Study and Impact Assessment, 66-68 Hills Road Cambridge, CB2 1LA, 2010.

Gao Z., Smith D. E., Daw C., Edwards K., Kaul B.C., Domingo N., Parks J.E., Jones P.T., The evaluation of developing vehicle technologies on the fuel economy of long-haul trucks, Energy Conversion and Management, 16, 2015, 766-781.

Hsu F.H., Davis R. L., Drag reduction of tractor-trailers using optimized add-on devices, Journal of Fluids Engineering, 132(8), 084504. doi:10.1115/1.4001587.

Mazyan W. I., Numerical simulations of drag-reducing devices for ground vehicles, Doctoral dissertation, American University, 2013.

Ortega J., Salari K., Brown A., Schoon R., Aerodynamic drag reduction of class 8 heavy vehicles: a full-scale wind tunnel study, LLNL-TR-628153 report, 2013.

Bruneau C. H., Gilliéron P., Mortazavi I., Flow manipulation around the Ahmed body with a rear window using passive strategies, Comptes Rendus Mecanique, 335, 2007, 213-218.

Singh N. S., Rai L., Puri P. Bhatnagar A., Effect of moving surfaces on the aerodynamic drag of road vehicles, Proceeding IMechE. Part D: Journal of Automobile Engineering, 219, 2005, 803-816.

Håkansson C., Lenngren M. J., CFD Analysis of Aerodynamic Trailer Devices for Drag Reduction of Heavy Duty Trucks, Master's Thesis in the Master's programme Automotive Engineering, Chalmers University of Technology, Göteborg, Sweden 2010.

Khaled M, Elhage H, Harambat F, Peerhossaini H. Some innovative concepts for car drag reduction: A parametric analysis of aerodynamic forces on a simplified body, Journal of Wind Engineering and Industrial Aerodynamics, 107-108, 2012, 36-47.

Kassim Z.M., Filippone A., Fuel savings on a heavy vehicle via aerodynamic drag reduction, Transportation Research Part D: Transport and Environment, 15, 2010, 275-284.

Englar R.J., Advanced Aerodynamic Devices to Improve the Performance, Economics, Handling and Safety of Heavy Vehicles, SAE Technical Paper, 2001, 2001-01-2072.

Hyams G.D., Sreenivas K., Pankajakshan R, Nichols S, Briley R.D., Whitfield D.L. Computational simulation of model and full scale Class 8 trucks with drag reduction devices, Computers \& Fluids, 41, 2011, 27-40.

Mashadi B., Mahmoodi-k M., Ahmadizadeh P., Oveisi A., A path-following driver/vehicle model with optimized lateral dynamic controller, Latin American Journal of solid and structures, 11, 2014, 613-630.

Montazeri-Gh M., Mahmoodi-K. M., An optimal energy management development for various configuration of plug-in and hybrid electric vehicle, Journal of Central South University, 22, 2015, 1737-1747.

Stenvall H., Driving resistance analysis of long haulage trucks at Volvo, Master's Thesis in Automotive engineering, Chalmers University of Technology, Göteborg, Sweden, 2010. 